\title{
Analysis of Fume Formation Rate and Fume Particle Composition for Gas Metal Arc Welding (GMAW) of Plain Carbon Steel Using Different Shielding Gas Compositions
}

\author{
Kristin R. CARPENTER, ${ }^{1)}$ Brian J. MONAGHAN ${ }^{21}$ and John NORRISH ${ }^{3 \prime}$ \\ 1) Development Metallurgist, Product Technology, BlueScope Steel, Five Islands Rd, Port Kembla, NSW 2505, Australia. \\ E-mail: Kristin.carpenter@bluescopesteel.com \\ 2) School of Mechanical Materials and Mechatronics Engineering and \\ BlueScope Steel Metallurgy Centre, University of Wollongong, Wollongong, NSW, 2522, Australia. \\ 3) Welding Engineering Research Group, University of Wollongong, Wollongong, NSW, 2522, Australia.
}

(Received on September 1, 2008; accepted on December 27, 2008)

\begin{abstract}
The present paper compares thirteen shielding gases and their impact on FFR and fume particle while welding in the spray transfer regime. There was no obvious influence from the shielding gas on particle composition and fume particles were identified as $(\mathrm{Fe}, \mathrm{Mn})_{3} \mathrm{O}_{4}$. There was a slight peak shift that indicated that small levels of $\mathrm{Mn}$, as detected by TEM-EDS, substituted for $\mathrm{Fe}$ in the $\mathrm{Fe}_{3} \mathrm{O}_{4}$ phase.

Shielding gas composition is an important parameter for successful gas metal arc welding (GMAW) and has been shown to affect the fume formation rate (FFR). In Ar-based mixtures, increasing $\mathrm{CO}_{2}$ had a greater impact than raising $\mathrm{O}_{2}$ on FFR. When $\mathrm{O}_{2}$ was increased in ternary mixtures, the FFR increased for Ar$5 \% \mathrm{CO}_{2}$ but no discernable increase was observed for the $\mathrm{Ar}-12 \% \mathrm{CO}_{2}$ mixtures. Results indicate that $\mathrm{CO}_{2}$ additions in Ar-based shielding gases are the controlling factor in determining FFR due to the effect of $\mathrm{CO}_{2}$ on welding arc characteristics. Ar- $\mathrm{He}-\mathrm{CO}_{2}$ mixtures had the most stable FFR's.
\end{abstract}

KEY WORDS: shielding gas; fume formation rate; fume composition; GMAW.

\section{Introduction}

The generation of welding fumes during Gas metal arc welding (GMAW) is an inevitable part of the process. Welding fumes consist of metal oxide particles that can remain suspended and if inhaled by welders it can affect their health. ${ }^{1-3)}$ The chemical composition of the fume particulates and the FFR are important parameters in determining the potential dangers of welding fumes. ${ }^{3,4)}$

Gas metal arc welding (GMAW) is an important industrial process used for the joining of metals. The generation of welding fumes during arc welding processes is inevitable and are potentially hazardous to the welder's health. Welding fumes consist of metal oxide particles that can remain suspended in the air and thus, inhaled by welders. ${ }^{1-3)}$ The chemical composition and particle size of the fume particulates are important parameters in determining the toxicity of welding fumes. ${ }^{3,4)}$

The chemical composition and the fume formation rate (FFR) depends on several factors, namely, the welding parameters and processes, the filler and base materials and the shielding gas. ${ }^{5-7)}$ Due to the high temperatures involved with the welding arc, metal vapours are thought to predominately originate from the molten tip of the welding electrode, ${ }^{8)}$ though the molten weld pool is also a significant source. ${ }^{1,6)}$ Critical factors controlling the FFR/are, arc temperature, surface area of the wire tip and the size of droplets exposed to the arc hot zone. ${ }^{9,10)}$ Arc characteristics are strongly determined by the arc current and voltage. As a result current and voltage become critical factors controlling the FFR. ${ }^{1,3,5)}$

The oxygen content of the shielding gas, the proportion of $\mathrm{CO}_{2}$ and $\mathrm{O}_{2}$, is claimed to directly affect the FFR. ${ }^{5,11)}$ In particular, FFR increases with increasing $\mathrm{CO}_{2}$ additions in Ar-based shielding gases. ${ }^{3,5,12}$ The influence of oxygen content on fume particle chemistry is less well understood.

The observation of oxygen increasing fume formation is consistent with Turkdogen's oxidation enhanced evaporation model for steelmaking fumes, ${ }^{13,14)}$ where metal vapour reacts with oxygen near the surface of the metal, forming oxide and as a consequence enhancing fume formation. Ioffe et al., ${ }^{10)}$ based on Turkdogen's oxidation enhanced evaporation model, suggested that oxidation of liquid iron on the droplet surface, as opposed to oxidation of iron vapour, would occur if the oxygen concentration exceeded a critical concentration of approximately $10 \%$. However, Dennis et al. ${ }^{15)}$ reports that oxidation enhanced vaporisation would be unlikely to occur due to the large temperature variation between the molten droplet and the surrounding plasma, as well as the extremely high temperatures involved.

This paper will address the influence of the shielding gas on the chemical composition and FFR of welding fumes generated by robotic GMAW of plain carbon steel. TEM- 
EDS analysis was used to determine the chemical compositions of the fume particles and X-ray diffraction (XRD) to identify the bulk phases of the fume.

\section{Experimental Procedures}

The nominal chemical composition of the base plate and welding wire were $0.22 \mathrm{wt} \% \mathrm{C}, 1.6 \mathrm{wt} \% \mathrm{Mn}$ and $0.55 \mathrm{wt} \%$ $\mathrm{Si}$ and $0.08 \mathrm{wt} \% \mathrm{C}, 1.16 \mathrm{wt} \% \mathrm{Mn}$ and $0.7 \mathrm{wt} \% \mathrm{Si}$, respectively. The welding parameters were chosen to achieve spray transfer for all shielding gases. A WITT KM 30-4 gas mixer was used to generate the shielding gas mixtures listed in Table 1.

Gas metal arc welding (GMAW) of plain carbon steel (10 mm thick) was carried out with a Cigweld Trans Robot WS-0550 linked to a Fronius Trans Synergic 4000 power supply and wire feed system. The welding parameters were; AWS A5.18 (ER70S-6) uncoated, $1.2 \mathrm{~mm}$ diameter wire, $32 \mathrm{~V}$, wire feed rate $8 \mathrm{~m} \mathrm{~min}^{-1}$, contact tip to work distance (CTWD) of $20 \mathrm{~mm}$, gas flow rate of $20 \mathrm{~L} \mathrm{~min}^{-1}$, weld travel speed of $300 \mathrm{~mm} \mathrm{~min}^{-1}$ and direct current (electrode positive). Using the above welding parameters typically produced currents of $280 \pm 10 \mathrm{~A}$.

In Table 1, results are also given for; FFR, oxygen index and the TEM-EDAX results. The oxygen index was calculated using the simple IIW (International Institute of Welding) empirical formula, $\left(\% \mathrm{O}_{2}+0.5 \% \mathrm{CO}_{2}\right)$, which was used to estimate the 'oxidising effect' of the shielding gas. ${ }^{16,17)}$ This 'oxidising effect' is generally referred to as 'oxygen potential' in welding literature. The above formula was based on oxygen analysis of weld metal. Gas-weld metal interactions are much better characterised and understood than fume condensation and fume condensate-gas systems in welding. Given our uncertainty of the reactions taking place, the species present and the prevailing reaction temperature the usefulness of such a function is limited. Oxygen index is used here simply as a basis for comparison.

A Platon flowmeter was placed between the gas mixer and welding machine to ensure a constant flow-rate. The flow meter was calibrated with air using a water displacement test, where the flow rate was calculated by measuring the time taken for a given volume of water to be displaced by the gas. The flow meter reading was then corrected for the selected gas composition using gas density corrections, by using Eq. (1).

$$
F_{\text {gas }}=\frac{F_{\text {air }}}{k}, \quad k=\sqrt{r}
$$

Where $F_{\text {gas }}$ is the flow rate of the selected gas, $F_{\text {air }}$ is the flow rate for air and $k$ is a constant based on the relative gas density to air, $r$, at constant temperature and pressure. The values used for, $r$, were; $\mathrm{Ar} 1.380, \mathrm{CO}_{2} 1.520$, He 0.138 and $\mathrm{O}_{2} 1.105$ and ideal gas-mixing was assumed to calculate the density for each gas mixture.

For FFR determination, arc time was limited to $20 \mathrm{~s}$ to prevent clogging of the filter paper. Pall type A/E glass fibre filters were used, with a nominal pore size of $1 \mu \mathrm{m}$ and a typical thickness of $330 \mu \mathrm{m}$. A Sartorius balance (Model CP225D) was used to weight the filter paper before and after the test to obtain the mass of fume generated to five
Table 1. Shielding gas mixtures used for robotic GMAW, FFR results, $\mathrm{O}_{2}$ index and average particle composition.

\begin{tabular}{|c|c|c|c|c|c|c|}
\hline Gas composition & $\begin{array}{c}\text { FFR } \\
\left(\mathrm{g} \mathrm{min}^{-1}\right)\end{array}$ & $\begin{array}{c}\mathrm{O}_{2} \\
\text { Index }\end{array}$ & $\begin{array}{c}0 \\
\text { (wt\%) }\end{array}$ & $\begin{array}{c}\text { Si } \\
\text { (wt\%) }\end{array}$ & $\begin{array}{c}\mathrm{Mn} \\
\text { (wt\%) }\end{array}$ & $\begin{array}{c}\mathrm{Fe} \\
(w t \%)\end{array}$ \\
\hline Ar- $5 \% \mathrm{O}_{2}$ & 0.274 & $5 \%$ & 27.5 & 0.9 & 8.7 & 62.8 \\
\hline $\mathrm{Ar}-5 \% \mathrm{CO}_{2}$ & 0.246 & $2.5 \%$ & 27.5 & 0.7 & 7.0 & 64.8 \\
\hline Ar- $10 \% \mathrm{CO}_{2}$ & 0.298 & $5 \%$ & 27.4 & 0.3 & 5.9 & 66.4 \\
\hline Ar- $18 \% \mathrm{CO}_{2}$ & 0.396 & $9 \%$ & 28.1 & 1.3 & 4.2 & 66.3 \\
\hline Ar-5\% $\% \mathrm{CO}_{2}-2 \% \mathrm{O}_{2}$ & 0.242 & $4.5 \%$ & 27.5 & 0.6 & 7.4 & 64.5 \\
\hline Ar- $12 \% \mathrm{CO}_{2}-2 \% \mathrm{O}_{2}$ & 0.312 & $8 \%$ & 27.8 & 1.0 & 5.8 & 65.3 \\
\hline Ar- $18 \% \mathrm{CO}_{2}-2 \% \mathrm{O}_{2}$ & 0.392 & $11 \%$ & 28.4 & 2.3 & 7.0 & 62.3 \\
\hline Ar-5\% $\% \mathrm{CO}_{2}-5 \% \mathrm{O}_{2}$ & 0.352 & $7.5 \%$ & 28.1 & 1.6 & 6.1 & 64.2 \\
\hline Ar- $12 \% \mathrm{CO}_{2}-4 \% \mathrm{O}_{2}$ & 0.318 & $10 \%$ & 28.1 & 1.6 & 6.1 & 64.2 \\
\hline Ar- $12 \% \mathrm{CO}_{2}-6 \% \mathrm{O}_{2}$ & 0.332 & $12 \%$ & - & - & - & - \\
\hline Ar-20\%He-12\%CO & 0.279 & - & 28.1 & 1.3 & 4.0 & 66.6 \\
\hline Ar- $30 \% \mathrm{He}-6 \% \mathrm{CO}_{2}$ & 0.273 & - & 27.7 & 0.8 & 6.1 & 65.4 \\
\hline Ar- $30 \% \mathrm{He}-10 \% \mathrm{CO}_{2}$ & 0.277 & - & 27.7 & 0.8 & 4.8 & 66.8 \\
\hline
\end{tabular}

decimal places. The fume box design originated from the recommendations of international standard ISO15011-1, ${ }^{19}$ ) but a number of modifications have been made to cater for the robot arm movement; sliding doors were fitted to the rear opening of the fume enclosure.

Fume was collected for TEM analysis on an aluminium SEM stub during the welding onto a plain carbon steel plate in a fume box. The stub was in a fixed position $30 \mathrm{~mm}$ from the centre line of the arc in the welding direction and $50 \mathrm{~mm}$ above the plate. This position was chosen to provide sufficient fume collection for TEM analysis, as determined from previous work. ${ }^{18)}$ Fume particles were washed off the stub by ultrasonic agitation into a bath of ethanol, where the ethanol was pre-filtered through $0.22 \mu \mathrm{m}$ micro-pore filter to remove contaminates. This mixture was then deposited onto holey carbon-coated TEM copper grids. Chemical analysis was performed with TEM-EDS, using a Jeol JEM 2011 at $200 \mathrm{KV}$ equipped with a $\mathrm{Si}(\mathrm{Li})$ detector, using a double tilt beryllium holder.

To identify bulk phases in the fume, a GBC Scientific Equipment, MMA X-ray diffractometer was used. Scans were conducted from $15^{\circ}$ to $75^{\circ} 2 \theta$ at a rate of $1^{\circ} \mathrm{min}^{-1}$, step size 0.02 and with the X-ray source running at $1.0 \mathrm{~kW}$ $(35 \mathrm{kV}$ and $28.8 \mathrm{~mA})$. Fume was transferred from the filter paper onto a low-background quartz slide, where a thin layer of petroleum jelly was used to adhere the fume to the slide.

\section{Results}

\subsection{XRD}

There was no evidence using XRD that shielding gas composition affected the composition of the bulk fume. XRD analysis of the (bulk) fume identified the $\mathrm{Fe}_{3} \mathrm{O}_{4}-$ spinel type phase (Magnetite-index card 011-0614 ICDD data base). There was a slight peak shift that indicated that small levels of Mn, as detected by TEM-EDS, substituted 
for $\mathrm{Fe}$ in the $\mathrm{Fe}_{3} \mathrm{O}_{4}$ phase. This is consistent with other studies reported in the literature. ${ }^{20,21)}$

\subsection{TEM-EDS}

Fume particles were composed mainly of Fe-oxide $\left(\mathrm{Fe}_{3} \mathrm{O}_{4}\right)$ and contained a small amount of $\mathrm{Mn}$ and trace amounts of Si. The average compositions, included in Table 1 , were determined by TEM-EDS for a number of particles for each shielding gas mixture. Results suggest that there was significant enrichment $\mathrm{Mn}$ in the fume (4-8 wt\%) compared to the base steel $(1.6 \mathrm{wt} \%)$ or wire composition $(1.16 \mathrm{wt} \%)$. Silicon levels in the fume were similar to the wire composition but EDS results showed that small peaks of $\mathrm{Si}$ and $\mathrm{O}$ were present in the background when the electron beam was focused on the carbon film. It is likely that the trace amounts of $\mathrm{Si}$ and $\mathrm{O}$, about $0.2-0.5 \mathrm{wt} \%$, were at least in part from O-ring grease contamination from TEM sample holders. The presence of $\mathrm{Si}$ in fume particles is widely known but with this background contamination it is impossible to accurately determine the amount of $\mathrm{Si}$ in the fume particles.

\subsection{Fume Morphology}

Figure 1 shows a typical TEM image, taken at $200 \mathrm{Kx}$, of a mixture of spherical and faceted particles, including the tendency of the particles to agglomerate in groups and chain-like structures. TEM observations yielded no evidence of metal core-oxide shelled particles in any test condition, which have previously been reported in the literature. $^{22)}$ In previous work, ${ }^{23)}$ the authors showed the crystalline nature of the fume particles as evidenced from the lattice fringes.

\subsection{Fume Emissions}

FFR was expressed as the weight of fume generated per unit of arc time $\left(\mathrm{g} \mathrm{min}^{-1}\right)$ and is the mean of three measurements for each test. Over the entire test range, the majority of measurements had a scatter of less than $\pm 3.7 \%$. The maximum scatter was $\pm 7.6 \%$ around the mean and is consistent with FFR measurements made to international standard ISO15011-1.

In Fig. 2 the FFR is plotted as a function of shielding gas composition, where each region on the graph groups FFR results according to different variables of the shielding gas mixtures. FFR increased with increasing $\mathrm{CO}_{2}$ for the binary $\mathrm{Ar}-\mathrm{CO}_{2}$ mixtures. For $\mathrm{Ar}-5 \% \mathrm{O}_{2}$, FFR increased slightly over that for $\mathrm{Ar}-5 \% \mathrm{CO}_{2}$ but was less than that for $\mathrm{Ar}-$ $10 \% \mathrm{CO}_{2}$, the binary $\mathrm{CO}_{2}$ mixture with the equivalent oxygen index. FFR increased with increasing $\mathrm{CO}_{2}$ in the ternary $\mathrm{CO}_{2}+2 \% \mathrm{O}_{2}$ mixtures but the addition of $2 \% \mathrm{O}_{2}$ had no impact on the FFR when compared to equivalent binary mixtures. When the $\mathrm{O}_{2}$ was increased in the ternary mixtures, the FFR increased at the $5 \% \mathrm{CO}_{2}$ level but at $12 \%$ $\mathrm{CO}_{2}$, given the scatter in experimental data, there was no discernable increase. For the He group, there was no significant change in the FFR indicating that minor $\mathrm{CO}_{2}$ and/or He variations have an insignificant influence.

It is thought that the oxygen content of the shielding gas has a direct influence on amount of fume generated. Therefore, FFR as a function of oxygen index for the $\mathrm{Ar}-\mathrm{O}_{2}, \mathrm{Ar}-$ $\mathrm{CO}_{2}$ and $\mathrm{Ar}-\mathrm{CO}_{2}-\mathrm{O}_{2}$ series was plotted in Fig. 3. From Fig.

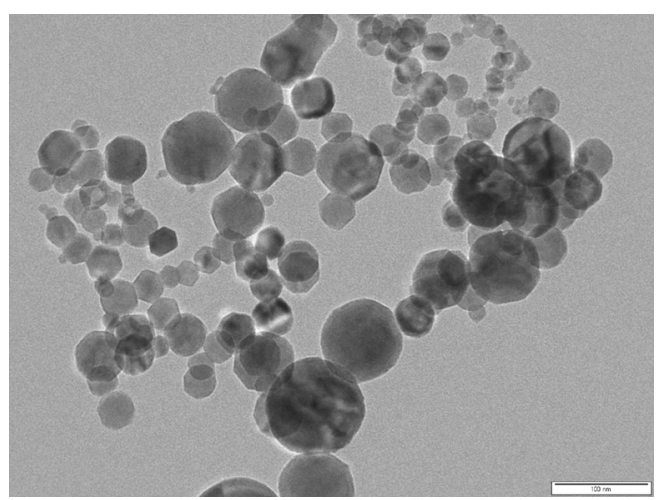

Fig. 1. Typical bright field TEM image at $200 \mathrm{Kx}$ showing welding fumes with a mixture of particle sizes, with either spherical or faceted morphology and often in chain-like structures (shielding gas: $\mathrm{Ar}-10 \mathrm{CO}_{2}$ ).

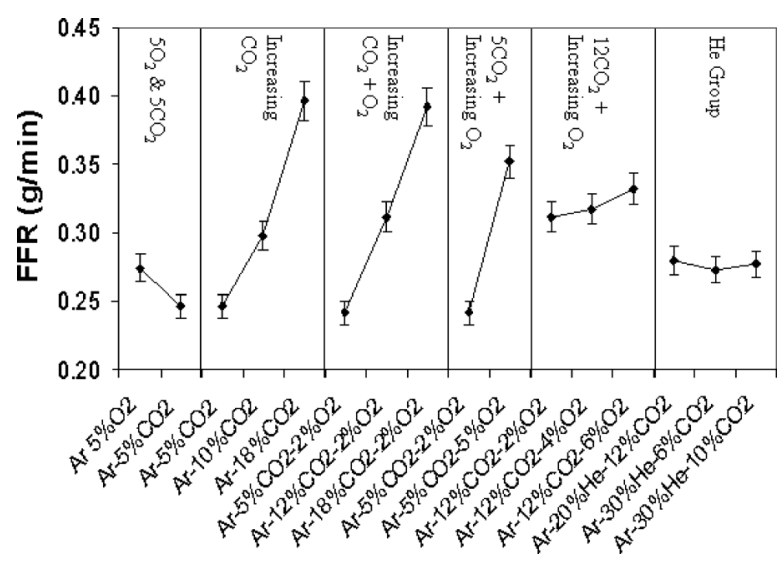

Fig. 2. FFR as a function of shielding gas composition under the same welding conditions. Each region on the graph groups the shielding gas mixtures according to different variables in the composition.

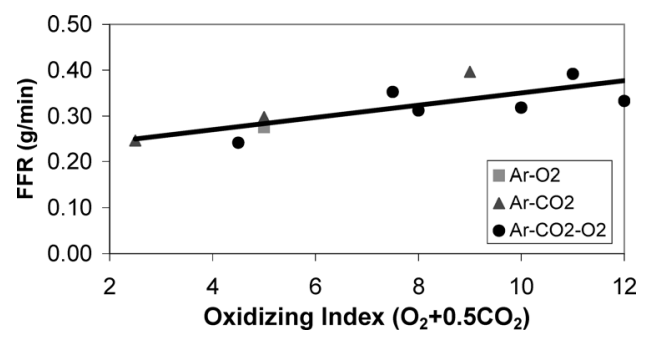

Fig. 3. FFR plotted against oxygen index for the $\mathrm{Ar}-\mathrm{O}_{2}, \mathrm{Ar}-\mathrm{CO}_{2}$ and $\mathrm{Ar}-\mathrm{CO}_{2}-\mathrm{O}_{2}$ series.

3, a weak trend of FFR increasing with oxygen index was observed.

\section{Discussion}

Results presented in Figs. 2 and 3 show several anomalies to the view that FFR is a function of the oxygen index of the shielding gas. Firstly, Fig. 3 showed a weak trend of increasing FFR with increasing oxygen index and considerable scatter. Secondly, the addition of $2 \%$ oxygen to the $\mathrm{Ar}-\mathrm{CO}_{2}$ mixtures had no influence on FFR. This is illustrated more clearly in Fig. 4, where the FFR results for Ar$\mathrm{CO}_{2}$ and $\mathrm{Ar}-\mathrm{CO}_{2}-2 \% \mathrm{O}_{2}$ showed identical curves. Finally, there was no discernable increase in FFR for the 


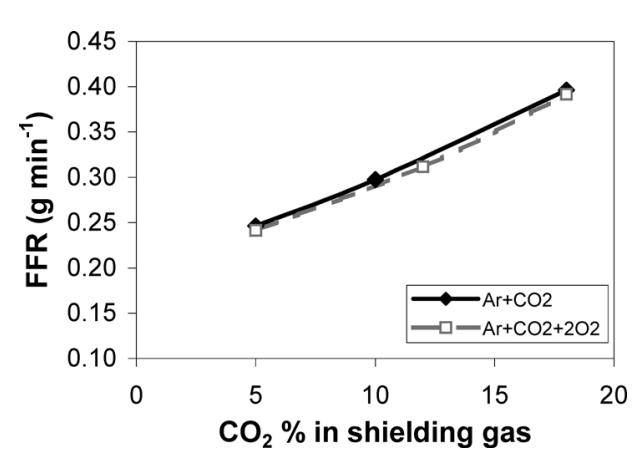

Fig. 4. FFR plotted as a function of $\% \mathrm{CO}_{2}$ in shielding gas for $\mathrm{Ar}-\mathrm{CO}_{2}$ and $\mathrm{Ar}-\mathrm{CO}_{2}-2 \% \mathrm{O}_{2}$.

$\mathrm{Ar}-12 \% \mathrm{CO}_{2}$ ternary mixtures when oxygen was increased from 2 to $6 \%$. This corresponds to a large increase in the oxygen index of $50 \%$. If oxygen index was the controlling factor, it would be reasonable to expect that a $50 \%$ increase would yield a noticeable increase in FFR.

The argument for oxygen index controlling FFR was essentially based on Turkdogan's et al. ${ }^{13)}$ oxidation enhanced vaporisation work. The rate of evaporation from molten metal was estimated from the Langmuir equation when derived in a vacuum, which gives the maximum possible evaporation rate.

$$
J_{\max }=\frac{p}{\sqrt{2 \pi R T M}}
$$

Where $p$ is pure vapour pressure, $R$ is the gas constant, $T$ is temperature $(\mathrm{K})$ and $M$ is the molar weight of the metal vapour. For a given temperature, the rate of vaporisation (fume formation) will increase with increasing partial pressure of oxygen in the atmosphere (oxygen index). Therefore, increasing the amount of active components in the shielding gas could enhance fume formation but results have shown that this does not always take place.

Two critical factors linked to increasing FFR are droplet temperature and the amount of the droplet's surface exposed to highest temperatures, or droplet size. The Langmuir equation is also dependent on temperature and it is feasible that temperature is the controlling factor in determining the FFR. An increase in the surface temperature of a droplet has been shown to be a critical controlling factor in fume formation. $1,9,10,24)$

In previous work, ${ }^{23)}$ the average fume particle size was shown to increase as the $\mathrm{O}_{2}$ and $\mathrm{CO}_{2}$ components of the shielding gas increased. This was explained by the increase in $\mathrm{O}_{2}$ and $\mathrm{CO}_{2}$ promoting a higher driving force for nucleation, thus promoting increased nucleation at higher temperatures, which would be more favourable for the formation of coarser particles. Droplet size is also a key factor in determining FFR for two main reasons; 1) increased surface area available for vaporisation and 2) increasing droplet size tends to increase droplet temperature., ${ }^{9,24)}$

Figure 4 showed that FFR had a strong correlation with increasing the $\mathrm{CO}_{2}$ concentration in argon based shielding gases. Pires ${ }^{25)}$ found that $\mathrm{CO}_{2}$ additions had a stronger influence on FFR than oxygen additions in Ar-based shielding gas. It is proposed that it is the effect of $\mathrm{CO}_{2}$ on weld metal transfer and arc characteristics, not just the increase in oxygen index that is responsible for higher FFR's. It is known that increasing $\mathrm{CO}_{2}$ levels in argon based shielding gases tends to reduce arc stability. ${ }^{26)}$ For example, Pires et $a l^{25)}$ produced transfer maps for different shielding gas mixtures and found that arc stability decreased with increasing $\mathrm{CO}_{2}$ for binary mixtures. A decrease in arc stability would likely lead to larger droplets with longer dwell times (detachment time) increasing the exposure of the droplet forming at the end of the electrode to the hot arc zone and consequently generating more fume. ${ }^{8)}$ Rhee and $\mathrm{Kanateyasibu}^{27}$ discovered that droplet size increased as the percentage of $\mathrm{CO}_{2}$ in argon shielding gas increased over a range of currents (242-342 A). As noted earlier, an increase in droplet size and consequently, an increase in droplet surface temperature and exposure to the arc, would enhance fume formation.

In Fig. 2, $\mathrm{Ar}-5 \% \mathrm{O}_{2}$ recorded a higher FFR than for $\mathrm{Ar}-$ $5 \% \mathrm{CO}_{2}$; based on this, it would be expected that the addition of $\mathrm{O}_{2}$ to binary $\mathrm{Ar}-\mathrm{CO}_{2}$ mixtures would increase the FFR, rather than have little to no effect. The low FFR for $\mathrm{Ar}-5 \% \mathrm{CO}_{2}$ in Fig. 2 is consistent with work reported by Voitkevich. ${ }^{3)}$ Voitkevich investigated the effect of the percentage $\mathrm{O}_{2}$ and $\mathrm{CO}_{2}$ in argon shielding gas on FFR. In Voitkevich's study, when increasing $\mathrm{O}_{2}$ from 0 to $6 \%$, there was a relatively sharp, linear increase in FFR, while increasing $\mathrm{CO}_{2}$ showed a minimum FFR rate at $4-5 \% \mathrm{CO}_{2}$. Heile and $\mathrm{Hill}^{5)}$ graphed the effect of voltage and current on FFR when welding with $\mathrm{Ar}-5 \% \mathrm{O}_{2}$ shielding gas and the voltage corresponding to the minimum fume generation was below $32 \mathrm{~V}$, even at a relatively high current of $350 \mathrm{~A}$. Operating at $32 \mathrm{~V}$, as is the case in the setup used in this investigation, does not provide ideal welding conditions for $\mathrm{Ar}-5 \% \mathrm{O}_{2}$ and therefore a higher FFR would be expected.

Conducting the welding experiments for this work at a fixed voltage of $32 \mathrm{~V}$ may also explain why the addition of $2 \% \mathrm{O}_{2}$ to the binary $\mathrm{Ar}-\mathrm{CO}_{2}$ shielding gas mixtures had little to no effect on FFR for the given experimental procedures. It is well known that low additions of $\mathrm{O}_{2}$ or $\mathrm{CO}_{2}$ to argon shielding gas mixtures provide good arc stability during welding, which is characterised by lower operating voltages. ${ }^{30)}$ Further more, ternary $\mathrm{Ar}-\mathrm{CO}_{2}-\mathrm{O}_{2}$ mixtures have also been noted for providing improved arc stability. ${ }^{25,30}$ ) Operating at a fixed voltage would negate any influence small additions of $\mathrm{O}_{2}$ would have on the welding characteristics and consequently, the binary and ternary $\mathrm{Ar}-\mathrm{CO}_{2}$ based mixtures produced the same FFR result. It is suggested that conducting experiments to establish the optimum welding conditions, then determining the FFR, may improve the understanding of the influence of $\mathrm{O}_{2}$ additions in the ternary gas mixtures.

\section{Fume Composition}

TEM-EDS and XRD was used to identify $\mathrm{Fe}_{3} \mathrm{O}_{4}$ as the dominant phase of the fume composition. It was expected that $\mathrm{Mn}$ substituted for $\mathrm{Fe}$ in the $\mathrm{Fe}_{3} \mathrm{O}_{4}$ structure because there was no evidence of $\mathrm{MnO}$ in XRD results. This is very likely to occur as the $\mathrm{Mn}$ atom is of a similar size to that of $\mathrm{Fe}$ and is known to be able to substitute for Fe in solid solutions. Furthermore, the $\mathrm{Fe}_{3} \mathrm{O}_{4}-\mathrm{Mn}_{3} \mathrm{O}_{4}$ system is reproduced from the Slag Atlas ${ }^{28)}$ in Fig. 5, showing extensive solubil- 


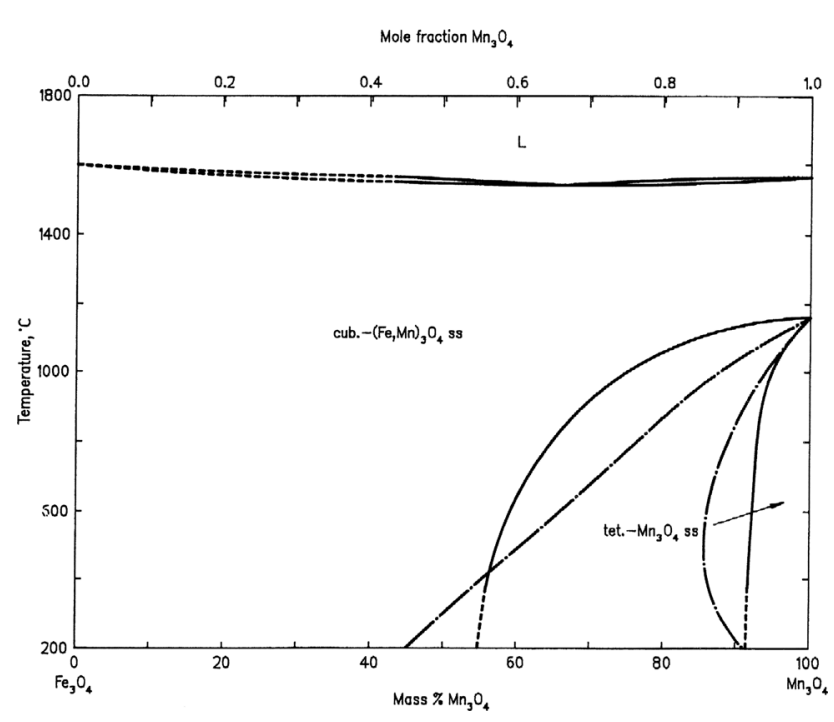

Fig. 5. $\mathrm{Fe}_{3} \mathrm{O}_{4}-\mathrm{Mn}_{3} \mathrm{O}_{4}$ system, showing an extensive region of cubic $(\mathrm{Fe}, \mathrm{Mn})_{3} \mathrm{O}_{4}$ solid solution, reproduced from the Slag Atlas. ${ }^{28}$

ity of $\mathrm{Mn}$ in $\mathrm{Fe}_{3} \mathrm{O}_{4}$ (Cubic-(Fe,Mn) $)_{3} \mathrm{O}_{4} \mathrm{ss}$ ).

The measured levels of $\mathrm{Si}$ in the fume are mostly below the detection capabilities of XRD so it is difficult to determine if $\mathrm{Si}$ was present in the form of a siliceous compound, such as $\mathrm{SiO}_{2}$ or if $\mathrm{Si}$ was incorporated into the $(\mathrm{Fe}, \mathrm{Mn})_{3} \mathrm{O}_{4}$ structure. The $\mathrm{Si}$ atom is also similar in size to the $\mathrm{Fe}$ atom but has a higher valence of $4+$, therefore according to the Hume-Rothery rules for solubility only partial solubility would be expected. ${ }^{29)}$ The uniform, crystalline nature of the fume particles (Fig. 1) and the detection of $\mathrm{Mn}$ and $\mathrm{Si}$ in all particles suggest that fume particles were $(\mathrm{Fe}, \mathrm{Mn})_{3} \mathrm{O}_{4}$ with trace $\mathrm{Si}$ additions.

TEM-EDS results showed no discernable trend in particle composition as a function of shielding gas composition signifying that shielding gas has no apparent effect on particle composition. A small variation of fume composition with particle size may be the source of the observed scatter in the results. ${ }^{23)}$

\section{Conclusions}

This paper studied the influence of shielding gas composition on FFR and particle composition for robotic GMAW of mild steel. Fume collection tests showed that FFR was strongly affected by increasing $\mathrm{CO}_{2}$ additions for both binary and ternary $\mathrm{Ar}-\mathrm{CO}_{2}-\mathrm{O}_{2}$ mixtures. The addition of $2 \%$ $\mathrm{O}_{2}$ to binary $\mathrm{Ar}-\mathrm{CO}_{2}$ mixtures had no effect on FFR. This was attributed to the fixed voltage welding conditions negating any influence of the addition of $2 \% \mathrm{O}_{2}$ to the binary $\mathrm{Ar}-\mathrm{CO}_{2}$ mixtures to the FFR. When the $\mathrm{O}_{2}$ was increased in the ternary mixtures, the FFR increased at the $5 \% \mathrm{CO}_{2}$ level but no discernable increase was observed for the $12 \% \mathrm{CO}_{2}$ mixtures. Increasing $\mathrm{He}$ or $\mathrm{CO}_{2}$ in ternary $\mathrm{Ar}-\mathrm{He}-\mathrm{CO}_{2}$ mixtures had little impact on the FFR.

The results obtained have shown that oxygen index only weakly correlates with FFR. A strong correlation of increasing FFR with increasing $\mathrm{CO}_{2}$ concentrations in argon based shielding gases was obtained. This was attributed to the influence of $\mathrm{CO}_{2}$ on metal transfer and arc characteris- tics (decreasing arc stability), where increased $\mathrm{CO}_{2}$ content would promote larger droplets, longer detachment times, higher arc temperatures and consequently, increased fume generation.

The combination of TEM-EDS with XRD identified fume particles as $(\mathrm{Fe}, \mathrm{Mn})_{3} \mathrm{O}_{4}$ with trace additions of $\mathrm{Si}$. It was found that shielding gas composition had no obvious effect on fume composition. However, enrichment of $\mathrm{Mn}$ in the fume composition was observed.

\section{Acknowledgement}

The funding for this project was provided by Linde-BOC Gases, Australia.

\section{REFERENCES}

1) H. R. Castner: Weld. J., 74 (1995), 59

2) P. J. Hewitt: Indoor Built Environ., 5 (1996), 253.

3) V. Voitkevich: Welding Fumes: Formation, Properties and Biological Effects, Abington Publishing, Cambridge, England, (1995), 1.

4) J. Hewitt and A. A. Hirst: Ann. Occup. Hyg., 35 (1991), 223.

5) F. Heile and D. C. Hill: Weld. J., 54 (1975), 201.

6) Y. Jin: Staub-Reinhalt. Luft, 54 (1994), 67.

7) Z. Sterjovski, J. Brossier, E. de Thoisy, D. Cuiuri, J. Norrish and B. Monaghan: Aust. Weld. J., 51 2006, 34.

8) M. Kobayashi, S. Maki, Y. Hashimoto and T. Suga: Weld. J., 62 (1983), 190.

9) R. T. Deam, S. W. Simpson and J. Haidar: J. Phys. D: Appl. Phys., 33 (2000), 1393.

10) I. Ioffe, D. MacLean, N. Perelman, I. Stares and M. Thornton: $J$. Phys D: Appl Phys., 28 (1995), 2473.

11) C. N. Gray, P. J. Hewitt and R. Hicks: Proc. Biennial Cornell Electrical Engineering Conf., 1 Cornell University, N.Y. (1980), 167.

12) D. E. Hilton and P. N. Plumridge: Weld. Metal. Fab., 59 (1991), 555.

13) E. T. Turkdogan, P. Grieveson and L. S. Darken: J. Phys. Chem., 67 (1963), 1647.

14) E. T. Turkdogan and L. E. Leake: J. Iron Steel Inst., 6 (1959), June, 162.

15) J. N. Dennis, P. J. Hewitt, C. J. Redding and A. D. Workman: Ann. Occup. Hyg., 45 (2001), 105.

16) A. A. Smith: Weld. World, 16 (1978), 25.

17) N. Stenbacka and K.-A. Persson: Weld. J., 68 (1989), 41.

18) S. Zhou, J. Norrish and Z. Chen: Proc. of Materials 98, The Biennial Conf. of the Inst. of Materials Eng., Wollongong, (1998), 295.

19) Int. standard: 'ISO 15011-1:2002: Health and safety in welding and allied processes - Laboratory method for sampling fume and gases generated by arc welding-Part 1: Determination of emission rate and sampling for analysis of particulate fume'; (2002).

20) N. T. Jenkins and T. W. Eagar: Weld. J., 84 (2005), 87s.

21) J. W. Sowards: Weld. World, 50 (2006), 40.

22) P. Konarski, I. Iwanejko and M. Cwil: Vacuum, 70 (2003), 385.

23) K. R. Carpenter, B. J. Monaghan and J. Norrish: ISIJ Int., 48 (2008), 1570 .

24) N. T. Jenkins, P. F. Mendez and T. W. Eagar: Proc. of the Int. Conf. Trends in Welding Research, Pine Mountain, GA, United States, (2005), 491.

25) I. Pires, L. Quintino and R. M. Miranda: Mater. Des., 28 (2007), 1623.

26) R. L. O'Brien and L. P. Connor: 'Welding Handbook', AWS, Miami, (1991), 133.

27) S. Rhee and E. Kannatey-Asibu: Weld. J., 71 (1992), 381s.

28) M. Allibert, H. Gaye, J. Gieseler, D. Janke, B. J. Keene, D. Kirner, M. Kowalski, J. Lehmann, K. Mills, D. Neuschutz, R. Parra, C. Saint-Jours, P. Spencer, M. Susa, M. Tmar and E. Woermann: Slag Atlas, Verlag Stahleisen GmbH, Germany, (1995), 73.

29) J. Shackelford: Introduction to Materials Science for Engineers, Macmillian Publishing Company, London, (1992), 133.

30) J. Norrish: Advanced Welding Processes Institute of Physics Publishing, Bristol, (1992), 82. 